\title{
Benefit of HSP90 $\alpha$ intervention on ischemia-reperfusion injury of venous blood-congested flaps
}

\author{
XIAO-YING HU ${ }^{1,2}$, ZHEN-YU CHEN ${ }^{1}$, BIN ZHANG ${ }^{1}$, XIANG-FENG LENG ${ }^{1}$, \\ XIAO-JIAN FAN ${ }^{2}$ and TAO LIU $^{3}$ \\ ${ }^{1}$ Department of Plastic and Cosmetic Surgery, Affiliated Hospital of Medical College, Qingdao University, \\ Qingdao, Shandong 266003; Departments of ${ }^{2}$ Breast Surgery and ${ }^{3}$ Otolaryngology, \\ Qingdao Eighth People's Hospital, Qingdao, Shandong 266100, P.R. China
}

Received February 1, 2016; Accepted May 6, 2016

DOI: $10.3892 /$ etm.2016.3317

\begin{abstract}
In order to decrease the incidence of flap necrosis after reconstructive surgeries, new approaches are required. In the present study, a model of venous congested flaps in rats was established to test the heat shock protein (HSP) $90 \alpha$, 'F-5', protein as an intervention therapy to alleviate ischemia-reperfusion injury. A recombinant plasmid pET15b-F-5 carrying the $H S P 90 \alpha$ gene was constructed and the induced protein was purified from bacterial cell cultures. The rats in the study were divided into three different intervention groups: group A rats were treated with normal saline prior to flap establishment, group B rats were treated with $\mathrm{HSP} 90 \alpha$, 'F-5', protein prior to flap establishment, and group $\mathrm{C}$ rats were treated with the same ' $\mathrm{F}-5$ ' protein after the surgical procedure. Additionally, the reperfusion time-points, ischemia for 6 or $8 \mathrm{~h}$ (5 rats each), were established in each group. After set periods of time, the flaps were observed for skin appearance, blood flow, survival rate and histological changes including neovascularization and re-epithelialization. The results showed that the flaps in the rats pre-treated with ' $\mathrm{F}-5$ ' protein performed better than the flaps of rats in the other two groups: the blood flow was higher, flap survival rate was increased, inflammatory cell infiltration was decreased and angiogenesis increased, and new skin structure was better completed by the end of the experiment. The parameters examind were improved for all the groups when the ischemia time was $6 \mathrm{~h}$ instead of $8 \mathrm{~h}$. In conclusion, HSP90 $\alpha$ intervention prior to flap establishment was shown to be beneficial in the model of ischemia-reperfusion injury in venous-congested flaps.
\end{abstract}

Correspondence to: Dr Zhen-Yu Chen, Department of Plastic and Cosmetic Surgery, Affiliated Hospital of Medical College, Qingdao University, 111 Jiangxi Road, Qingdao, Shandong 266003, P.R. China

E-mail: aygve07344gsx@163.com

Key words: heat shock protein 90, 'F-5 gene', venous blood-congested flap, ischemia-reperfusion injury

\section{Introduction}

Heat shock proteins (HSPs) are a set of stress response proteins, expressed in all living prokaryotic and eukaryotic cells by stimuli such as increasing temperatures, infection by a pathogen, ischemia, hypoxia, physical or chemical factors (1). Recent findings have shown a protective effect of of HSPs in flap ischemia-reperfusion injuries. It seems the high expression of HSP90 in local tissues after transplantation with pedicles or free flaps can significantly improve the survival rate of the skin flap (2). Ischemic preconditioning can upregulate the expression of the HSP9O gene (3), and HSP90 inhibitors can significantly inhibit the survival rate of flap (4). Upregulation of the HSP9O gene can be examined as a potential approach to improve the survival rate of transplanted flaps (5).

The majority of previous studies are based on arterial ischemic flap models (6). However, the necrosis of transplanted flaps occurs more commonly due to a venous reflux disorder or other reasons in the actual clinical setting (7). Furthermore, whether HSP90 preconditioning of ischemia-reperfusion injuries can improve the survival rate of flaps and the optimal time to deal with the flaps remains to be investigated.

In the present study, a model of venous-congested flaps in rats was established to test the heat shock protein (HSP) $90 \alpha$, 'F-5', protein as an intervention therapy to alleviate ischemia-reperfusion injury.

\section{Materials and methods}

Experimental animals. A total of 30 healthy adult SPF Wistar male and female rats, aged 6-8 weeks, with an average weight of $250 \mathrm{~g}$ were provided by the Central Animal Laboratory of Medical College, Qingdao University (Shandong, China). The rats were first acclimatized to their new environment, under normal conditions with $12 \mathrm{~h} \mathrm{light/dark} \mathrm{cycles} \mathrm{and} \mathrm{at}$ a constant temperature of $23^{\circ} \mathrm{C}$. After coding each rat, the animals were randomly divided into three groups of 10 animals each: group A rats were injected with normal saline prior to flap transplantation, group B rats were injected with ' $\mathrm{F}-5$ ' gene expression protein at $1 \mathrm{mg} / \mathrm{ml}$ prior to flap transplantation, and group $\mathrm{C}$ rats with the same amount of 
gene expression protein after flap transplantation. The study was approved by the ethics committee of Medical College of Qingdao University.

Reagents used in the present study were: ABC IHC kit (Wuhan Boster Biological Technology, Ltd., Wuhan, China), CD31 monoclonal antibody (Millipore Corp., Billerica, MA, USA), PBS buffer (Beijing Noble Rider Technology Co., Ltd., Beijing, China), DAB kit (Beijing Zhongshan Golden Bridge Biotechnology Co., Ltd., Beijing, China), TRITC fluorescence labeled secondary antibody (Wuhan Boster Biological Technology, Ltd.), DAPI dye (Beijing Zhongshan Golden Bridge Biotechnology Co., Ltd.), and neutral balsam (neutral balsam (mounting medium) (Shanghai Sangon Biotechnology Co., Ltd., Shanghai, China). Instruments used were: PeriScan PIM3 laser Doppler blood flow imaging instrument (Perimed AB, Stockholm, Sweden), ESO60D digital camera (Canon, Inc., Tokyo, Japan), Plus v6.0 Image-Pro image analysis software (Microsoft Corporation, Redmond, WA, USA), laser scanning confocal microscope and image acquisition system (Olympus, Tokyo, Japan).

Establishment of the model of ischemia-reperfusion injury in venous blood-congested flap. Following the technique described by Petry and Worthman (8), a 3x6 cm axial flap was formed, with the shallow abdominal blood vessel bundle as a pedicle, in the right lower quadrant. The flap edge tissue to the deep fascia layer along the design marking was then cut. The distal end of the flap was lifted, using microsurgical instruments to separate the artery and vein carefully, the venous pedicle was clipped with a microvessel clamp to severe venous return, and the flap was then sutured in situ. After 6 or $8 \mathrm{~h}$, depending on the group of rats being treated, the flap was reopened again and the vascular clamp removed to allow for recanalization of the venous return to supply blood. The veins were observed under the operating microscope to ensure blood flow again and the ischemia-reperfusion model was successful. The flap was then sutured in situ again, and the same sterile material was used to cover the flap.

Construction of HSP90 a gene vector. To construct the pET15b-F-5 recombinant plasmid, primers were designed to amplify a fragment from the human HSP90 $\alpha$ cDNA published by GenBank ('5-GGATCCGATGCCTGAGGAAACCCAG-3' and '5-ACTGTCGGATCCTTAGTCTACTTCTTCCAT-3'), which included a $\mathrm{BamHI}$ restriction endonuclease site. The pET15b-F-5 recombinant plasmid was genetically engineered using the amplicon, and the correct insert sequence was verified by DNA sequencing of the final plasmid.

Purification of 'F-5' gene protein was performed by using pET15b-F-5 recombinant plasmid to transform BL21-CodonPlus (DE3)-RP-competent cells. Protein expression was induced with IPTG. Expression proteins were purified by nickel-nitrilotriacetic acid (Ni-NTA) metal affinity chromatography, concentrated using Centricon YM-50, and then further purified with fast protein liquid chromatography (FPLC) to a final concentration of $1 \mathrm{mg} / \mathrm{ml}$.

Qualitative and quantitative analysis of ' $\mathrm{F}-5$ ' gene expression protein was performed by producing a protein quantification standard curve with BSA, and the Bradford method was used for quantification. SDS-PAGE and western blot analysis were used to verify the identity of the purified protein,

Grouping method and observation indices. Two reperfusion time-points were established in each group, ischemia for 6 or 8 h, (with 5 rats in each time-point). After recanalization, saline or purified protein was instantly injected locally to the flap subcutaneous tissue layers. The injection site was divided into 10 points, each injection point $1 \mathrm{~cm}$ apart, and $0.1 \mathrm{ml} /$ point, for a total of $1 \mathrm{ml}$.

The general observation of the flaps was carried out by adhering to the following guidelines: i) Observation time: flaps were observed at regular intervals daily following surgery, for 1-14 days; ii) observation area: observation of the areas of the near, middle and distal ends of the flaps were recorded; and iii) observation items: determinations of the color, dermatoglyph presence, texture, capillary filling test, needle prick test and the presence of blisters were recorded for each flap.

A laser doppler flow meter was used to determine the flap blood flow after ischemia for a given time and then reperfusion. This was performed to determine whether the establishment of the model of ischemia-reperfusion injury in each flap was successful.

Subsequent to surgery, the survival rate of each flap was determined daily for 1-14 days. After immobilizing each animal, a digital camera was used to capture images of the flap area. The Image-Pro Plus v6.0 image analysis software was used to calculate the survival rate of the flap, uaing the equation: flap survival rate $=($ flap survival area/flap design area) $\mathrm{x} 100 \%$.

Histological examination was also performed. Animal models in each group were randomly selected at 1,3, 7, 10 and 14 days after surgery, then skin tissue from the central area of the flap was dissected, and any pathological changes of the flap were observed under the microscope using the H\&E (hematoxylin and eosin) staining method.

Immunohistochemical staining was used to detect angiogenesis and re-epithelialization of the flap. Briefly, the specimen materials were taken at 1, 3, 7, 10 and 14 days after operation, and cut into $5 \mu \mathrm{m}$ sections after paraffin embedding. After dewaxing and rehydration of the sections, rabbit polyclonal anti-CD31 antibody (dilution: 1:50) (Abcam, London, England; cat no.: ab28364) was added for incubation overnight at $4^{\circ} \mathrm{C}$. The following day the specimens were washed three times with PBS, prior to adding TRITC-labeled secondary antibody, and incubating at room temperature $\left(37^{\circ} \mathrm{C}\right)$ for $1 \mathrm{~h}$. The cell nucleus was stained with DAPI, washed three times with PBS, and mounted by neutral balsam. Using a laser scanning confocal microscope, the blood vessel density was contrasted by calculating the average number of blood vessels in the five random fields on each section. Immunohistochemistry was used to detect and compare the epithelium migration of the wound in each group.

Statistical methods. Using the SPSS statistical software for analysis, measurement data were presented as mean \pm SD. Comparison among groups was made using ANOVA analysis, and comparison were made between two groups using the independent-sample t-test. Enumeration data were expressed as cases or percentage, and comparison among groups were 
Table I. Comparisons of tissue perfusion parameters of blood flow, blood volume, mean transit time and permeability surface.

\begin{tabular}{llcccc}
\hline Parameters & & Lung cancer group $(\mathrm{n}=350)$ & Non-cancer group $(\mathrm{n}=62)$ & $\mathrm{t}$ & P-value \\
\hline Blood flow (ml/sec) & First time & $13.4 \pm 2.3$ & $3.6 \pm 0.4$ & 5.627 & 0.029 \\
& Second time & $14.2 \pm 2.5$ & $3.4 \pm 0.3$ & 5.839 & 0.026 \\
Blood volume (ml) & First time & $5.6 \pm 1.3$ & $1.3 \pm 0.4$ & 4.748 & 0.037 \\
& Second time & $5.8 \pm 1.2$ & $1.1 \pm 0.2$ & 4.923 & 0.034 \\
Mean transit time (msec) & First time & $23.4 \pm 3.6$ & $4.7 \pm 1.2$ & 6.626 & 0.025 \\
& Second time & $25.6 \pm 3.2$ & $4.3 \pm 1.1$ & 6.349 & 0.027 \\
Permeability surface & First time & $35.4 \pm 6.6$ & $10.2 \pm 3.1$ & 6.137 & 0.029 \\
& Second time & $36.6 \pm 5.8$ & $10.4 \pm 3.3$ & 6.602 & 0.031 \\
\hline
\end{tabular}

\section{Ischemia}

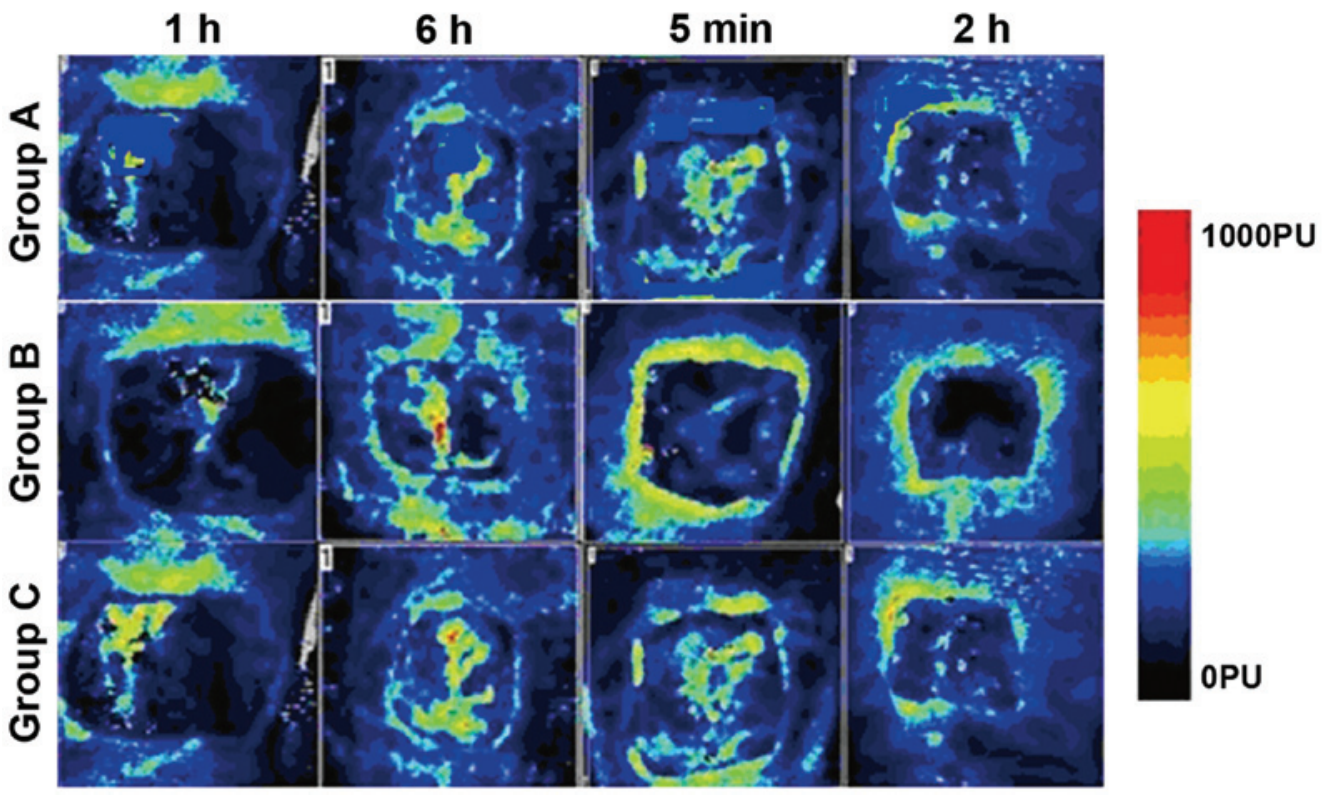

\section{Reperfusion}

Figure 1. Comparisons of flap blood flow by laser Doppler flow meter.

made using the $\chi^{2}$ test. $\mathrm{P}<0.05$ indicated statistically significant results.

\section{Results}

General observation of flap. The middle and distal ends of flaps showed pale or dark red coloring in each group at 1-2 days following surgery, with different degrees of swelling. The distal end of the flaps gradually blackened, the surface sank and a scab shell presented and poor flexibility was observed at 3-7 days. Generally after 7-10 days, the necrosis area of the flap was extended, and the wound surface under the black scab shell began to shrink with time. In addition, with time, the capillary filling time was extended, the dermatoglyphs disappeared, and the surface became shiny, with blisters or bleeding.

Flap blood flow. The flap blood flow in group B was significantly higher than that in groups $\mathrm{A}$ and $\mathrm{C}$ at all ischemia and reperfusion time-points. Group A had the lowest blood flow, and the difference was statistically significant $(\mathrm{P}<0.05)$. The blood flow to the flap was decreased in each group with the prolongation of ischemia, and it was increased with the prolongation of reperfusion time (Table I and Fig. 1).

Survival rate of flap. Following surgery, the survival rate of ischemia at 6 and $8 \mathrm{~h}$ in groups $\mathrm{B}$ and $\mathrm{C}$ was increased progressively with each passing time-point, and the survival rate in the group with ischemia for $6 \mathrm{~h}$ was higher than that in ischemia for $8 \mathrm{~h}$. The survival rate of group B was significantly higher than that of groups $\mathrm{A}$ and $\mathrm{C}$ at each time point, with group A having the lowest survival rates. The difference was statistically significant $(\mathrm{P}<0.05)$ (Table II).

Histological examination. A large number of infiltrating inflammatory cells were visible at wound tissues at postoperative day 1 in all the groups, and the angiotelectasis was obviously apparent. By day 7 , groups B and C showed inflammatory cell infiltration reduction, with the number of fibroblasts being increased, deeply stained, an increased capillary component, and the visible part of new epithelial tissues. 
Table II. Survival rate of flap (\%).

Post operation

\begin{tabular}{|c|c|c|c|c|c|c|c|c|c|c|}
\hline \multirow[b]{2}{*}{ Group } & \multicolumn{2}{|c|}{$\begin{array}{c}\text { Day } 1 \\
\text { Ischemia }\end{array}$} & \multicolumn{2}{|c|}{$\begin{array}{c}\text { Day } 3 \\
\text { Ischemia }\end{array}$} & \multicolumn{2}{|c|}{$\begin{array}{c}\text { Day } 7 \\
\text { Ischemia }\end{array}$} & \multicolumn{2}{|c|}{$\begin{array}{l}\text { Day } 10 \\
\text { Ischemia }\end{array}$} & \multicolumn{2}{|c|}{$\begin{array}{c}\text { Day } 14 \\
\text { Ischemia }\end{array}$} \\
\hline & $6 \mathrm{~h}$ & $8 \mathrm{~h}$ & $6 \mathrm{~h}$ & $8 \mathrm{~h}$ & $6 \mathrm{~h}$ & $8 \mathrm{~h}$ & $6 \mathrm{~h}$ & $8 \mathrm{~h}$ & $6 \mathrm{~h}$ & $8 \mathrm{~h}$ \\
\hline A & $12.3 \pm 3.6$ & $10.4 \pm 3.2$ & $15.6 \pm 3.3$ & $12.7 \pm 3.4$ & $18.2 \pm 3.7$ & $15.4 \pm 3.5$ & $19.3 \pm 3.8$ & $16.2 \pm 3.6$ & $21.3 \pm 3.5$ & $18.7 \pm 3.3$ \\
\hline B & $36.6 \pm 13.2$ & $30.3 \pm 14.6$ & $48.5 \pm 13.6$ & $36.9 \pm 15.4$ & $67.9 \pm 15.2$ & $59.5 \pm 15.5$ & $85.6 \pm 17.6$ & $76.9 \pm 18.2$ & $92.8 \pm 16.9$ & $84.8 \pm 17.4$ \\
\hline $\mathrm{C}$ & $32.1 \pm 10.3$ & $26.7 \pm 11.2$ & $42.7 \pm 12.6$ & $35.2 \pm 12.5$ & $63.5 \pm 21.7$ & $52.7 \pm 18.9$ & $78.9 \pm 20.5$ & $73.2 \pm 23.4$ & $86.5 \pm 24.7$ & $79.6 \pm 24.6$ \\
\hline F-value & 4.521 & 4.863 & 5.052 & 5.274 & 5.632 & 5.754 & 5.935 & 5.867 & 6.214 & 6.539 \\
\hline $\mathrm{P}$-value & 0.041 & 0.039 & 0.037 & 0.035 & 0.031 & 0.028 & 0.026 & 0.023 & 0.017 & 0.014 \\
\hline
\end{tabular}
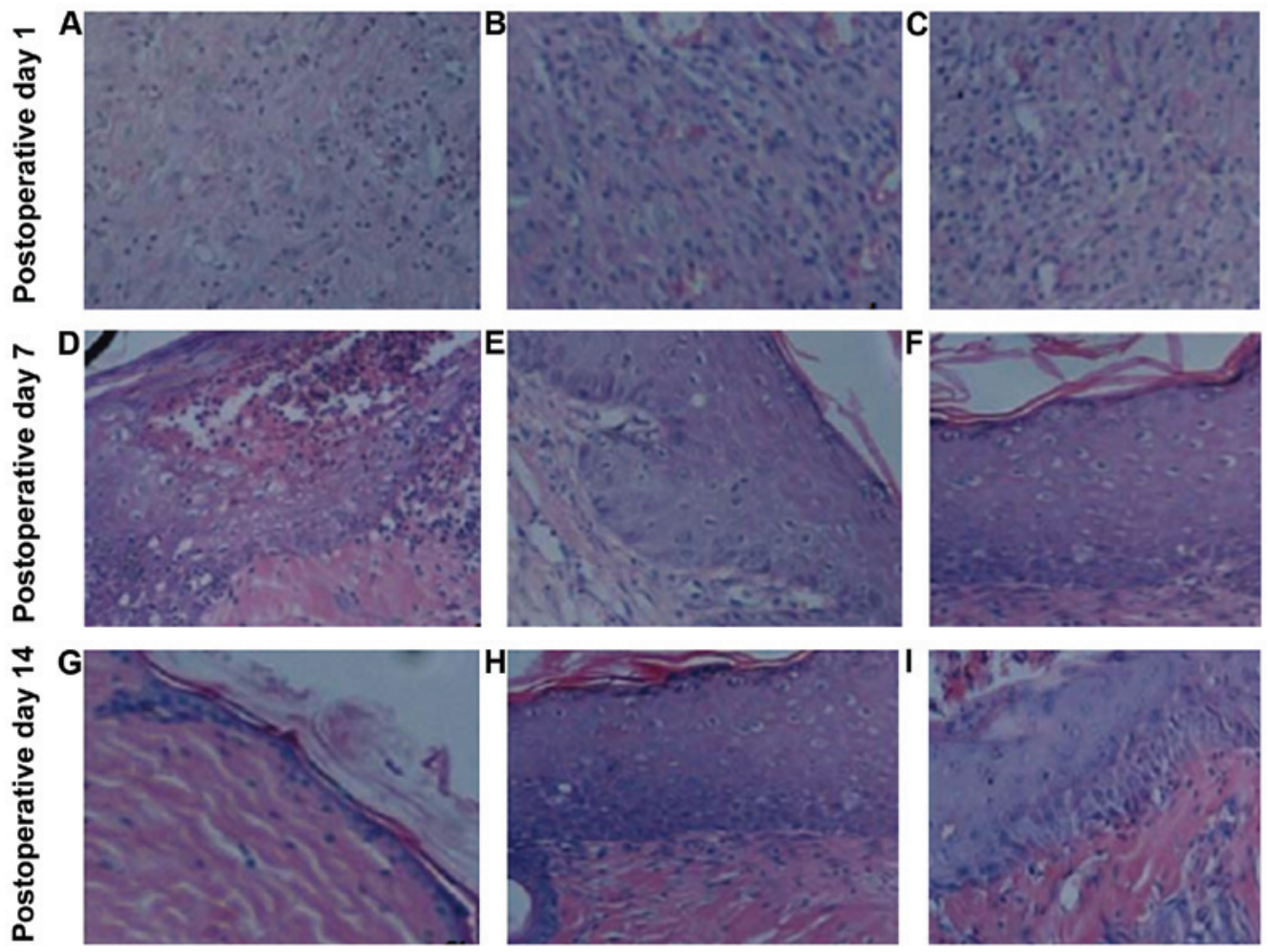

Figure 2. H\&E staining (magnification, x100). Postoperative day 1: A (group A), B (group B), and C (group C). Postoperative day 7: D (group A), E (group B), and F (group C). Postoperative day 14: G (group A), H (group B), and I (group C). H\&E, hematoxylin and eosin.

Group A, however, had abundant inflammatory cell infiltration, and less endothelial cell and fibroblast proliferation. At post-operative day 14 , groups B and C, showed new capillaries and inflammatory cell numbers were decreased further, while mature fibroblasts were increased, the cells were arranged in tidier bundles, the matrix components (red staining) were uniform, new epithelial tissues were increased, and there was visible basal cell hyperplasia (Fig. 2).

Angiogenesis and re-epithelialization. Following surgery, the neovascular densities in groups $\mathrm{B}$ and $\mathrm{C}$ with ischemia for 6 and $8 \mathrm{~h}$ were increased with each time-point, and the densities in rats subjected to ischemia for $6 \mathrm{~h}$ were higher than that in those with ischemia for $8 \mathrm{~h}$. The neovascular density of group B was significantly higher than that of group $\mathrm{C}$ at each time, group A had the lowest, and the difference was statistically significant $(\mathrm{P}<0.05)$ (Table III). The new skin was more abundant on the wound tissues in groups B and C, and even some new blood vessels were visible. At postoperative day 14, groups B and C showed a relatively complete new skin structure, and the spikes were visible at attachment of the epidermis and dermis, and the new blood vessels were increased (Fig. 3).

\section{Discussion}

In a previous study by Wang et al, HSP72 expression was induced in flaps by systemic and local preheating, thus achieving an increased flap survival area. Their results showed 
Table III. Neovascular density (no./horizon).

Post operation

\begin{tabular}{|c|c|c|c|c|c|c|c|c|c|c|}
\hline \multirow[b]{2}{*}{ Group } & \multicolumn{2}{|c|}{$\begin{array}{c}\text { Day } 1 \\
\text { Ischemia }\end{array}$} & \multicolumn{2}{|c|}{$\begin{array}{c}\text { Day } 3 \\
\text { Ischemia }\end{array}$} & \multicolumn{2}{|c|}{$\begin{array}{c}\text { Day } 7 \\
\text { Ischemia }\end{array}$} & \multicolumn{2}{|c|}{$\begin{array}{l}\text { Day } 10 \\
\text { Ischemia }\end{array}$} & \multicolumn{2}{|c|}{$\begin{array}{c}\text { Day } 14 \\
\text { Ischemia }\end{array}$} \\
\hline & $6 \mathrm{~h}$ & $8 \mathrm{~h}$ & $6 \mathrm{~h}$ & $8 \mathrm{~h}$ & $6 \mathrm{~h}$ & $8 \mathrm{~h}$ & $6 \mathrm{~h}$ & $8 \mathrm{~h}$ & $6 \mathrm{~h}$ & $8 \mathrm{~h}$ \\
\hline A & $0.2 \pm 0.1$ & $0.1 \pm 0.1$ & $0.3 \pm 0.1$ & $0.1 \pm 0.1$ & $0.5 \pm 0.2$ & $0.2 \pm 0.2$ & $0.6 \pm 0.2$ & $0.3 \pm 0.2$ & $0.8 \pm 0.3$ & $0.3 \pm 0.3$ \\
\hline B & $0.7 \pm 0.3$ & $0.5 \pm 0.3$ & $1.2 \pm 0.4$ & $0.8 \pm 0.4$ & $2.9 \pm 0.6$ & $1.7 \pm 0.5$ & $4.2 \pm 0.8$ & $3.5 \pm 0.9$ & $4.8 \pm 1.3$ & $4.3 \pm 1.2$ \\
\hline $\mathrm{C}$ & $0.5 \pm 0.2$ & $0.4 \pm 0.2$ & $0.9 \pm 0.4$ & $0.6 \pm 0.4$ & $2.5 \pm 0.9$ & $1.4 \pm 0.6$ & $3.9 \pm 1.3$ & $3.1 \pm 1.2$ & $4.4 \pm 1.5$ & $3.9 \pm 1.6$ \\
\hline F-value & 5.624 & 5.937 & 6.233 & 6.428 & 6.635 & 6.768 & 6.938 & 7.421 & 7.632 & 7.765 \\
\hline P-value & 0.037 & 0.035 & 0.032 & 0.026 & 0.024 & 0.017 & 0.014 & 0.013 & 0.012 & 0.011 \\
\hline
\end{tabular}
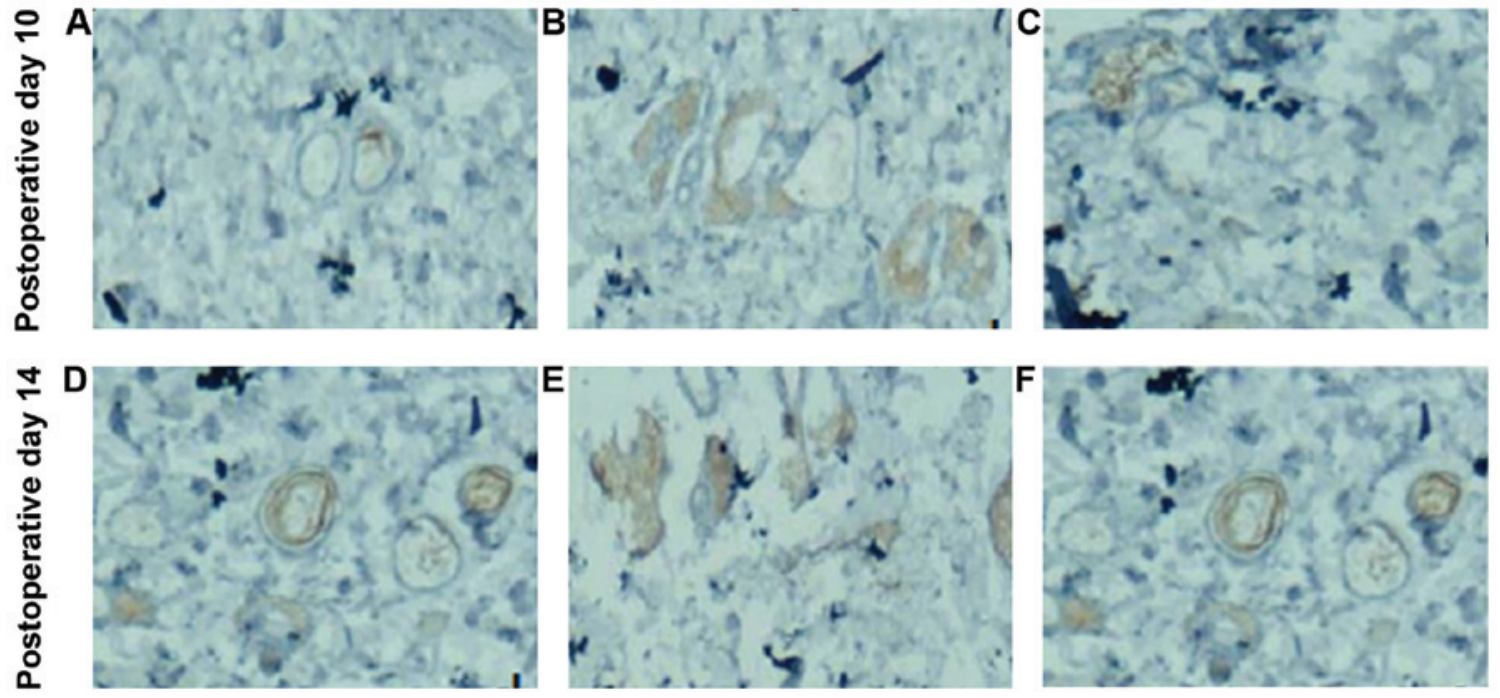

Figure 3. Immunohistochemistry (magnification, x40). Postoperative day 10: A (group A), B (group B), and C (group C). Postoperative day 14: D (group A), E (group B), and F (group C).

that HSP expression upregulation in flap tissues can protect cells and alleviate ischemia-reperfusion injury, and clearly improve tissue survival rates after transplantation (9). HSP90 is an important member of the HSPs family, with a molecular weight of 83-90 kDa, depending on the presence of $\alpha$ and $\beta$ subunits containing aspartic acid amide fragments, and the homology of the two subunits is $84 \%$. HSP90 exists in the form of $\alpha \alpha$ and $\beta \beta$, the amount of both is roughly equal, and both are cytoplasmic proteins. HSP90 is able to assist in protein folding and maintaining the stability of intracellular varieties of signaling proteins, thereby promoting cell survival and growth. In addition to the intracellular form, HSP90 $\alpha$ can also be secreted into the extracellular environment, and is therefore known as secretory HSP90. A previous study showed that the hypoxia-induced factor (HIF) increases under hypoxia, which may induce partial secretory HSP90 $\alpha$ to increase and therefore induce skin basal cells, while fibroblasts and vascular endothelial cells migrate to the wound, thereby promoting wound healing (10). Additionally, another study found that the secretion of HSP90 $\alpha$ is effective in the promotion of wound healing. In the same study, a highly conserved amino acid sequence (aa236 - aa350) located in HSP90 $\alpha$ was found, and expression of the polypeptide containing it was more effective than the full-length secretory HSP90 $\alpha$ in promoting wound healing. This functional gene sequence is known as 'F-5' gene (11). Therefore, for this study the F-5 sequence was induced in vitro to obtain the highly active F-5 protein.

For the present study, two blocking points of ischemia for 6 and $8 \mathrm{~h}$ were set to compare the effect of different intervention methods under different blocking times. These time-points were chosen based on the findings of a published study that established that in venous occlusions of $<6 \mathrm{~h}$, the flaps can survive after recanalization, whereas in venous occlusions for $8 \mathrm{~h}$, the majority of the flaps cannot survive, while in blocks for $10 \mathrm{~h}$, none of the flaps survive (12).

In this study, it was shown that the ischemia-reperfusion injury model in a venous blood-congested flap is stable and reliable. The benefit of the HSP90 preconditioning treatment on flap survival was clearly demonstrated by showing an increase in blood flow following recanalization, an increase in the flap survival rate, and improved immunohistochemical parameters of healing (lower cell infiltration, more neovascularization, 
and better epidermal re-structuring) when compared to the same observed variables in the flaps of rats treated with saline prior to the surgical procedure or with HSP90 following the surgical procedure. It was also clear that the flaps in all the groups were improved after an ischemia time of $6 \mathrm{~h}$ than after ischemia for $8 \mathrm{~h}$, and that all the parameters of healing were improved with time after the recanalization.

As endogenous HSPs are released in the body at determined times, the organism or tissue needs to spend an absolute recovery period after stimulation, during which cells synthesize HSPs, prior to sufficient HSPs being available to act on a given tissue (13). Future studies are needed to establish the timings and amounts of stimulation needed to generate protecting endogenous levels of HSP90 $\alpha$ in tissues to be subjected into surgical flap procedures.

Inconclusion, the HSP90 $\alpha$ intervention on venous-congested ischemia-reperfusion injured flaps can improve the survival rate, as the longer the ischemic time, the worse the effect.

\section{Acknowledgements}

The present study was funded by the Natural Science Foundation of Shandong Province.

\section{References}

1. Park CJ and Seo YS: Heat shock proteins: a review of the molecular chaperones for plant immunity. Plant Pathol J 31: 323-333, 2015.

2. Woodley DT, Wysong A, DeClerck B, Chen M and Li W: Keratinocyte migration and a hypothetical new role for extracellular heat shock protein 90 alpha in orchestrating skin wound healing. Adv Wound Care (New Rochelle) 4: 203-212, 2015.
3. Jayaprakash P, Dong H, Zou M, Bhatia A, O'Brien K, Chen M, Woodley DT and Li W: Hsp90 $\alpha$ and Hsp90 $\beta$ together operate a hypoxia and nutrient paucity stress-response mechanism during wound healing. J Cell Sci 128: 1475-1480, 2015.

4. Wright L, Barril X, Dymock B, Sheridan L, Surgenor A, Beswick M, Drysdale M, Collier A, Massey A, Davies N, et al: Structure-activity relationships in purine-based inhibitor binding to HSP90 isoforms. Chem Biol 11: 775-785, 2004.

5. Imai Y, Sakurai M, Horinouchi T, Lee YS and Yamada A: Epithelial cells and adipose cells both have their own temporal profile in $72-\mathrm{kd}$ heat-shock protein expression determining their tolerance for ischaemia. J Plast Reconstr Aesthet Surg 59: 230-238, 2006

6. Babovic S, Angel MF, Im MJ, Ress AM and Manson PN: Effects of tissue expansion on secondary ischemic tolerance in experimental free flaps. Ann Plast Surg 34: 593-598, 1995.

7. Hauge EM, Balling E, Hartmund T and Hjortdal VE: Secondary ischemia caused by venous or arterial occlusion shows differential effects on myocutaneous island flap survival and muscle ATP levels. Plast Reconstr Surg 99: 825-833, 1997.

8. Petry JJ and Wortham KA: The anatomy of the epigastric flap in the experimental rat. Plast Reconstr Surg 74: 410-413, 1984.

9. Wang BH, Ye C, Stagg CA, Lin M, Fawcett T, VanderKolk CA and Udelsman R: Improved free musculocutaneous flap survival with induction of heat shock protein. Plast Reconstr Surg 101: 776-784, 1998

10. Li W, Li Y, Guan S, Fan J, Cheng CF, Bright AM, Chinn C, Chen $M$ and Woodley DT: Extracellular heat shock protein-90alpha: Linking hypoxia to skin cell motility and wound healing. EMBO J 26: 1221-1233, 2007.

11. Cheng CF, Sahu D, Tsen F, Zhao Z, Fan J, Kim R, Wang X, O'Brien K, Li Y, Kuang Y, et al: A fragment of secreted Hsp90a carries properties that enable it to accelerate effectively both acute and diabetic wound healing in mice. J Clin Invest 121: 4348-4361, 2011.

12. Harashina T, Sawada Y and Watanabe S: The relationship between venous occlusion time in island flaps and flap survivals. Plast Reconstr Surg 60: 92-95, 1977.

13. Zhang Y, Bai X, Wang Y, Li N, Li X, Han F, Su L and Hu D: Role for heat shock protein $90 \alpha$ in the proliferation and migration of $\mathrm{HaCaT}$ cells and in the deep second-degree burn wound healing in mice. PLoS One 9: e103723, 2014. 